University of Wollongong

Research Online

Faculty of Engineering - Papers (Archive)

Faculty of Engineering and Information

Sciences

$1-1-2010$

\title{
Internal erosional behaviour of lignosulfonate treated dispersive clay
}

J S. Vinod

University of Wollongong, vinod@uow.edu.au

Buddhima Indraratna

University of Wollongong, indra@uow.edu.au

M A. A Mahamud

University of Wollongong, maam445@uow.edu.au

Follow this and additional works at: https://ro.uow.edu.au/engpapers

Part of the Engineering Commons

https://ro.uow.edu.au/engpapers/913

\section{Recommended Citation}

Vinod, J S.; Indraratna, Buddhima; and Mahamud, M A. A: Internal erosional behaviour of lignosulfonate treated dispersive clay 2010, 549-554.

https://ro.uow.edu.au/engpapers/913

Research Online is the open access institutional repository for the University of Wollongong. For further information contact the UOW Library: research-pubs@uow.edu.au 


\title{
INTERNAL EROSIONAL BEHAVIOUR OF LIGNOSULFONATE TREATED DISPERSIVE CLAY
}

\author{
J. S. VINOD*, BUDDHIMA INDRARATNA ${ }^{\dagger}$ \\ and $M$. A. A. MAHAMUD $\ddagger$ \\ School of Civil, Mining \& Environmental Engineering, \\ University of Wollongong, Wollongong City, NSW-2522, Australia \\ *vinod@uow.edu.au \\ tindra@uow.edu.au \\ †maam445@uow.edu.au
}

\begin{abstract}
Internal erosional behaviour of lignosulfonate treated dispersive clay has been studied using the Process Simulation Apparatus for Internal Crack Erosion (PSAICE) designed and built at UOW. Effectiveness of lignosulfonate treated dispersive clay on the erosion resistance has been investigated and its advantage over traditional admixtures is presented. Test results show that the hydraulic shear stress increases with increase in the amount of lignosulfonate. In addition, the micro-chemical analysis has been carried out using FTIR. Based on the Fourier Transform Infrared (FTIR) Spectroscopy results a stabilization mechanism has been proposed for lignosulfonate treated dispersive soil.
\end{abstract}

Keywords: Lignosulfonate; stabilization; micro-chemical analysis; internal erosional behavior.

\section{INTRODUCTION}

Rapid erosion of surface soil, internal washout and piping in embankments and dams containing dispersive and collapsible soils pose significant construction, stability and maintenance problems. Therefore, it is very important to improve the erosion resistance of soils in appropriate and cost effective manner. Chemical stabilization is an effective ground improvement technique for controlling erosion. However, all traditional chemical stabilizers (e.g. lime, cement, gypsum and flyash) are not readily acceptable due to stringent occupational health and safety issues and also pose threat to the environment by changing the soil $\mathrm{pH}$ which often limits the scope of vegetation plus causing ground water pollution. Moreover, the traditionally treated soils (highly cemented) have shown brittle behavior especially under cyclic loads, affecting the stability of rail embankments and aircraft runways. To overcome these difficulties, 
researchers are now looking for a new soil stabilizer, which is environmentally sustainable and also can overcome most of the adverse effects of traditional chemical stabilizers, apart from maintaining sufficient ductile properties of the soil, thereby preventing cracking. In the above context, lignosulfonate has shown a promising prospect as a stabilizing agent, especially for soft soils. It belongs to a family of lignin based organic polymers derived as a waste by-product from wood and paper processing industry. It is an environmental friendly, non-corrosive and non-toxic chemical that does not alter the soil $\mathrm{pH}$ upon treatment. In the recent past, investigations were carried out on cohesive soils with lignosulfonate as strength improving stabilizer (Puppala and Hanchanloet, 1999; Tingle and Santori, 2003). It is reported that lignosulfonate with sulphuric acid as additive showed a profound improvement in shear strength and resilient modulus of soil. Tingle and Santori (2003) investigated the effect of lignosulfonate on different clayey soils and found that lignosulfonate stabilizer significantly improved the strength of low plasticity clayey soils. In addition, a number of researchers have performed experiments to investigate whether this particular type of chemical in low volume road construction would improve the strength of sub-grade and control dust emission (Chemstab, 2003; Tingle and Santori, 2003). Recently, Indraratna et al. (2008) conducted a research on internal erosion behavior of lignosulfonate (LS) treated dispersive clayey soil using Process Simulation Apparatus for Internal Crack Erosion (PSAICE). This study is the extension of study done by Indraratna et al. (2008), where hydraulic shear behavior of LS treated dispersive clay has been investigated. However, the stabilization mechanism of LS treated soil still remains unclear. Present study explains the mechanism of lignosulfonate treated soil based on micro-chemical analysis.

\section{THEORETICAL BACKGROUND}

Internal erosion behavior of lignosulfonate treated and untreated soils were studied using Process Simulation Apparatus for Internal Crack Erosion (PSAICE). Predicted erosion rate and hydraulic shear stress were used to calculate the erosion parameters, namely, the critical shear stress and the coefficient of soil erosion. The critical shear stress, $\tau_{c}$, is defined as the minimum hydraulic shear stress necessary to initiate erosion. The critical shear stress is estimated by extrapolating the straight line to the zero erosion rate. The slope of the linear line was presumed to be the coefficient of soil erosion. It is found that the turbidity increases initially, and then decreases as erosion progresses (Indraratna et al. 2008a). However, the flow rate was observed to be increasing with time. The erosion rate, $\dot{\varepsilon}\left(\mathrm{kg} / \mathrm{s} / \mathrm{m}^{2}\right)$, can then be calculated using Eq. (1) as described by Indraratna et al. (2008a).

$$
\dot{\varepsilon}=\frac{k Q T}{\pi \phi_{t} l}
$$


where, $k\left(\mathrm{~kg} / \mathrm{m}^{3} / \mathrm{NTU}\right)$ is the empirical factor relating turbidity to the soil solids concentrated in the flow, $Q\left(\mathrm{~m}^{3} / \mathrm{s}\right)$ is the average flow rate through the soil crack, $T$ (NTU) is the average turbidity of the effluent, $\phi_{t}(\mathrm{~m})$ is the diameter of the soil crack at time $t$, and $l(\mathrm{~m})$ is the length of the soil crack. The range of $k$ values $(0.002-0.011)$ was obtained for treated and untreated dispersive clay

The hydraulic shear stress, $\tau(\mathrm{Pa})$, on the soil crack surface can be calculated from by Indraratna et al. (2008a):

$$
\tau=\frac{\rho_{w} g i \phi_{t}}{4}
$$

where, $\rho_{w}\left(\mathrm{~kg} / \mathrm{m}^{3}\right)$ is the density of the eroding fluid; $\mathrm{g}\left(\mathrm{m} / \mathrm{s}^{2}\right)$ is the gravitational acceleration; $i$ is the hydraulic gradient across the soil crack and $\phi_{t}(\mathrm{~m})$ is the diameter of the soil crack at time $t$.

\section{LABORATORY INVESTIGATION}

\subsection{Internal Crack Erosion Tests}

A series of internal crack erosion tests were conducted on dispersive clayey soil collected from Wakool, New South Wales (NSW), Australia. According to the standard pinhole test (ASTM D.4647), the dispersive clay are classified D2. The maximum dry density and optimum moisture content of the dispersive clay were found as $15 \mathrm{kN} / \mathrm{m}^{3}$ and $22 \%$, respectively. Furthermore, the liquid limit and plastic limit of the dispersive clay were found to be $47.6 \%$ and $29.4 \%$, respectively. Internal crack erosion studies were conducted using the PSAICE, which has been developed and built at University of Wollongong.

Various amounts of additive including lignosulfonate and cement $[(0.2 \%-0.6 \%)$, by dry weight of soil] were selected to stabilize the dispersive clay. The soil was mixed with the selected amounts of lignosulfonate additive and statically compacted to $95 \%$ of the dry density inside a copper mould having the dimensions of $72 \mathrm{~mm}$ in diameter and $100 \mathrm{~mm}$ in height. The prepared samples were wrapped in moisture proof bag and cured for seven days. After curing, these samples were immersed in the eroding fluid (tap water) until saturation. Subsequently, internal crack erosion tests (PSAICE) were carried out by forcing the eroding fluid through a $10 \mathrm{~mm}$ soil crack formed at the centre of the samples.

\section{RESULTS AND DISCUSSION}

It is observed from the Fig. 1 that the erosion rate and hydraulic shear stress follow a linear relationship and the slope represents the coefficient of soil erosion. As expected, critical shear stress increases and coefficient of soil erosion decreases with the increase of amount of lignosulfonate (Fig. 1a). The critical shear stress (minimum hydraulic shear stress required to initiate erosion) is estimated by extrapolating the straight 


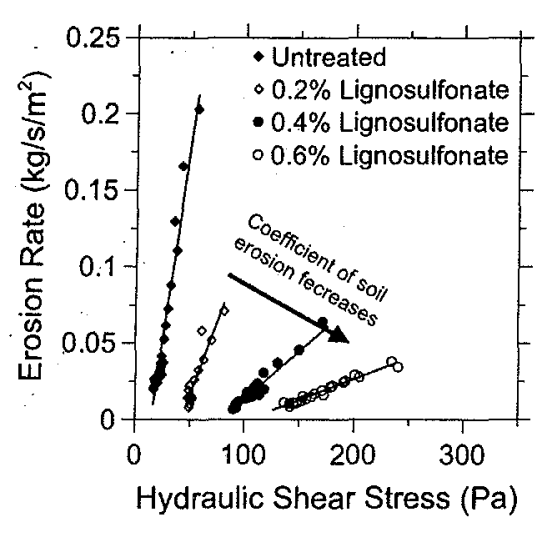

(a)

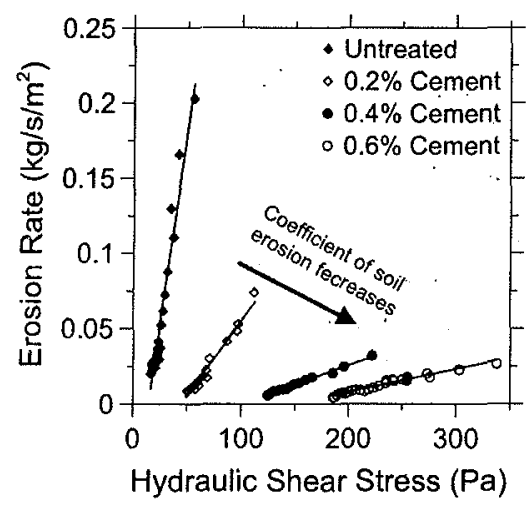

(b)

Figure 1. Erosion rate against hydraulic shear stress for lignosulfonate treated and cement treated dispersive-clay (Indraratna et al., 2008b).

line to the zero erosion rate. The critical shear stress increases from about $14 \mathrm{~Pa}$ to $105 \mathrm{~Pa}$ and coefficient of soil erosion decreases from 0.01 to 0.009 with the addition of lignosulfonate (Fig. 1a). The behaviour of lignosulfonate treated dispersive clay has been compared with cement treated soils (Fig. 1b). General purpose Portland cement was used for soil stabilisation and erosion tests were carried out on cement treated soils very similar to lignosulfonate stabilised soils. The cement treated soil exhibit a behaviour very similar to lignosulfonate treated soil.

\subsection{Micro-chemical analysis of treated and unfreated clay using Fourier Transform Infrared (FTIR) Spectroscopy}

Micro-chemical analysis was carried out using the Fourier Transform Infrared (FTIR) Spectroscopy. Each soil sample was scanned in terms of the wave number ranging from 4000 to $400 \mathrm{~cm}^{-1}$. The FTIR results were presented in the form of $\%$ transmittance versus the wave number. The transmittance is determined by the ratio of the intensity of transmitted beam to that of the incident beam. Figure 2 presents the results of FTIR analysis carried out on lignosulfonate admixture. It is evident from the Fig. 2(a) that lignosulfonate contains the functional groups such as benzene, $\mathrm{CH}, \mathrm{C}-$ $\mathrm{O}-\mathrm{C}, \mathrm{C}-\mathrm{O}, \mathrm{S}=\mathrm{O}$ and $\mathrm{OH}$. Moreover, the structure of the lignosulfonate is developed from the functional groups observed from FTIR analysis as presented in Fig. 2(b). In order to understand the behavior of lignosulfonate treated soil, FTIR tests were carried out on dispersive clay samples with and without chemical treatment (Fig. 3). The typical functional groups of the untreated soil are presented in Fig. 3(a). It is clear from Fig. 3(a) that the untreated dispersive clay contains functional groups such as $\mathrm{Si}-\mathrm{O}, \mathrm{Al}-\mathrm{O}-\mathrm{H}$ and $\mathrm{OH}$. However, FTIR results of treated soil exhibits functional 


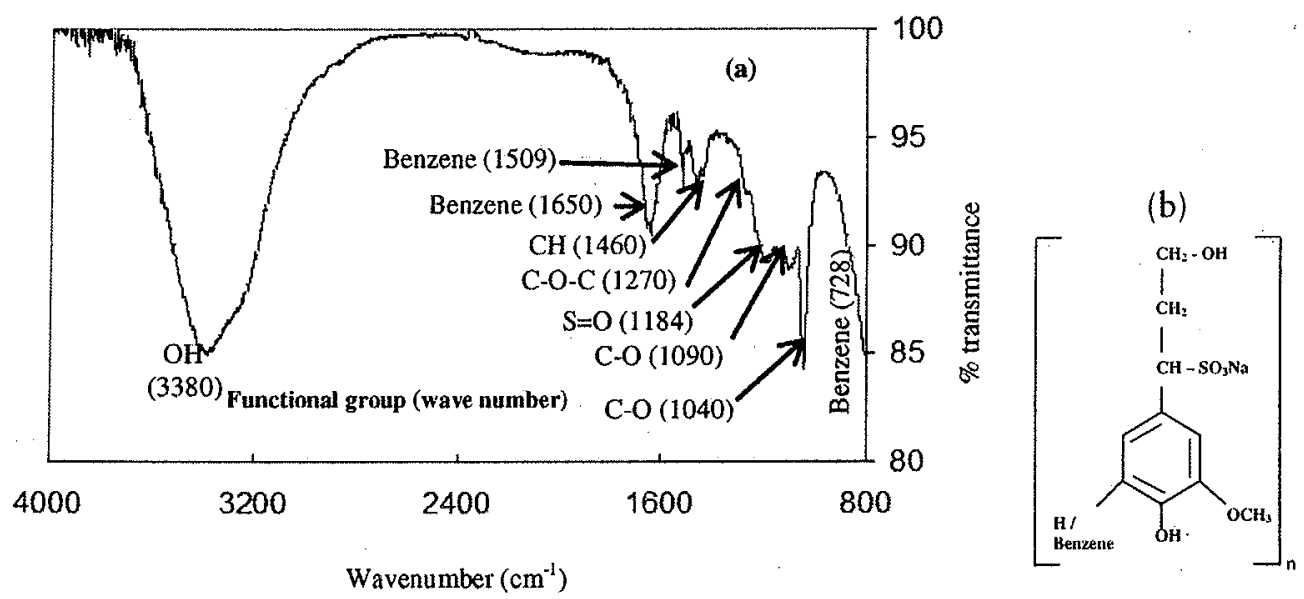

Figure 2. (a) FTIR result of lignosulfonate, (b) structure of lignosulfonate.
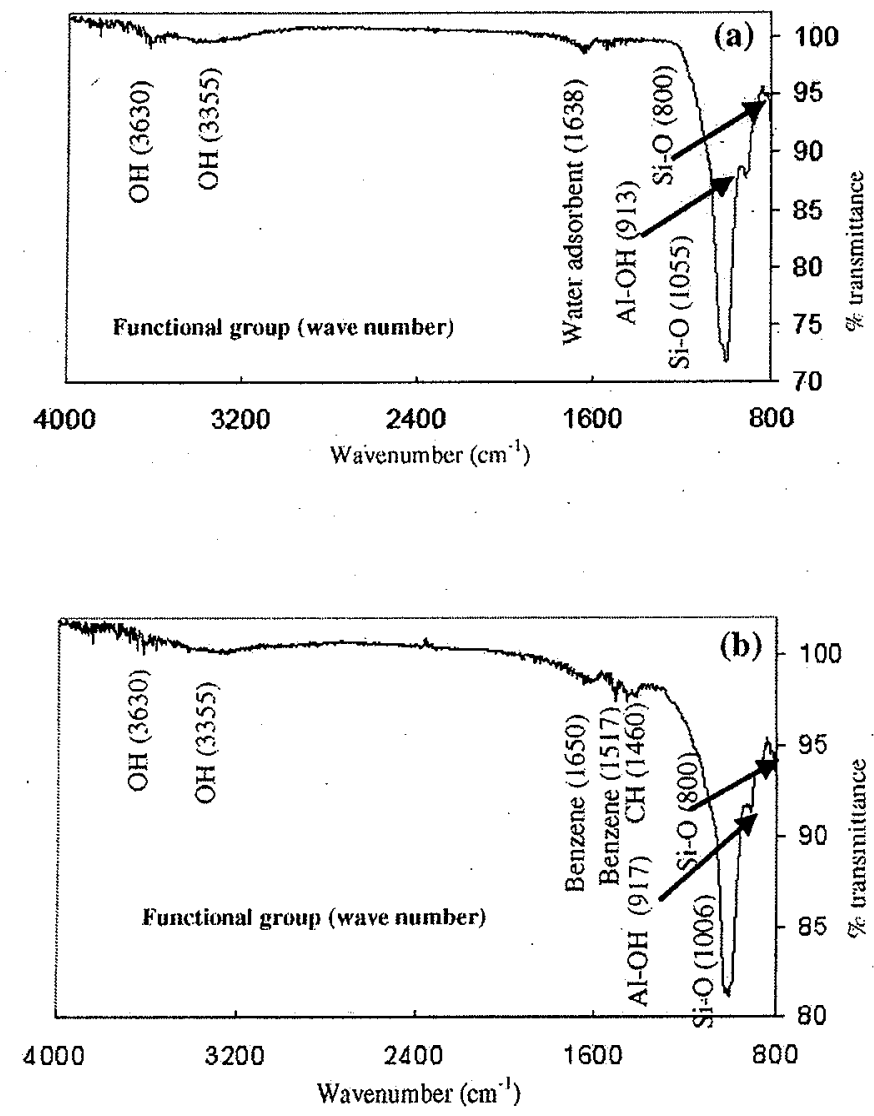

Figure 3. (a) FTIR result of dispersive clay; (b) lignosulfonate treated dispersive clay. 


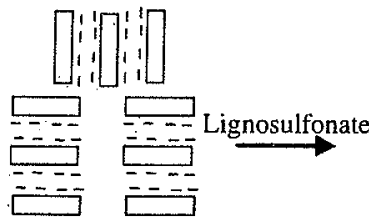

(a)

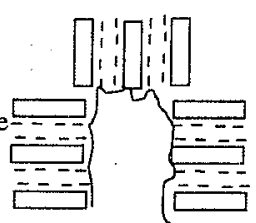

(b)

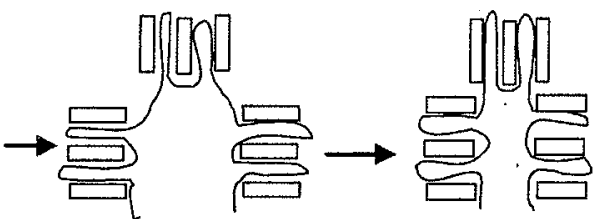

(c)

(d)

Figure 4. Schematic diagram of stabilization mechanism for lignosulfonate treated soil.

groups of both dispersive clay and lignosulfonate as expected. Moreover, there is a marked difference in the spectra (Figs. $3 \mathrm{a}$ and $3 \mathrm{~b}$ ) observed in the wave number ranging from $2000-1200 \mathrm{~cm}^{-1}$ for the case of lignosulfonate treated dispersive clay. This marked difference in the spectra observed for the treated dispersive soil is due to the micro-chemical reaction of lignosulfonate with the soil.

\subsection{Proposed Stabilization Mechanism of Lignosulfonate treated dispersive soil}

A schematic diagram (Fig. 4) explaining the mechanism of lignosulfonate treated soil has been developed based on the FTIR analysis. Figure 4(a) shows the untreated clay particles with negative charges in the interstitial layer of clay minerals. Once the clay particles are treated with lignosulfonate, the adsorption of lignosulfonate on the clay particle surface occurs (Fig. 4b). This adsorbed lignosulfonate neutralizes the negative charges of clay particles and bonds with clay mineral layers (Fig. 4c). Due to the neutralization of the surface charge, the double layer thickness decreases. Moreover the lignosulfonate polymer chains bridge the soil particles together and forms soil aggregates (Fig. 4d). The formation of soil aggregates after lignosulfonate treatment has been confirmed using SEM images (Indraratna et al., 2008a).

\section{CONCLUSIONS}

The erosion test results reveal that lignosulfonate increases the hydraulic shear stress of dispersive clay with the extent of chemical treatment. It is found that the critical shear stress of dispersive clay increases and the coefficient of soil erosion decreases with the lignosulfonate treatment, which is very similar to that of traditional admixtures. The improvement of performance exhibited by the lignosulfonate treated soil is attributed to the reduction of the double layer thickness by the neutralization action of surface charges of the clay particles by lignosulfonate. 


\section{ACKNOWLEDGEMENTS}

The Authors gratefully acknowledge the financial support provided by Queensland Department of Main Roads, Brisbane, and Chemstab consulting Pvt. Ltd., Wollongong, through an Australian Research Council (ARC) Linkage project. The Authors also wish to thank Dr. Thevaragavan Muttuvel for providing the experimental data for the current investigation.

\section{REFERENCES}

Chemstab, Technical Manual, CHEMSTAB Consulting Pty Ltd, Horsley, NSW Australia (2003).

B. Indraratna, T. Muttuvel, H. Khabbaz and B. Armstrong, Predicting the erosion rate of chemically treated soil using a process simulation apparatus for internal crack erosion, J. Geotechnical ơ Geoenvironmental Engineering, ASCE 134(6) (2008a) 837.

B. Indraratna, M. Thevaragavan and H. Khabbaz, Investigating erosional behaviour of chemically stabilised erodible soils, Geotechnical Special Publication 178, Geo-congress 2008, ASCE, (2008b) 670.

J. Puppala and S. Hanchanloet, Evaluation of a new chemical (SA-44/LS-40) treatment method on strength and resilient properties of a cohesive soil, paper presented at Transportation Research Board Annual Meeting (1999).

J. S. Tingle and R. L. Santori, Stablisation of clay soils with non traditional additives, Transporation Research Record No. 1819, National Research Council, Washington, 72 (2003). 